\title{
Sandfly (Diptera: Psychodidae: Phlebotominae) present in an endemic area of cutaneous leishmaniasis in West Boyacá, Colombia
}

\section{Flebótomos (Diptera: Psychodidae: Phlebotominae), presentes en una zona endémica de leishmaniasis cutánea en el occidente de Boyacá, Colombia}

\author{
David Camilo Martínez ${ }^{1,2}$ Julián Leonardo Ávila ${ }^{2,3}$ and Fredy Molano ${ }^{(\mathbb{D}}$ \\ 1 Universidad Pedagógica y Tecnológica de Colombia, Laboratorio de Entomología, Museo de Historia Natural \\ "Luis Gonzalo Andrade", Grupo de Investigación Sistemática Biológica-SisBio. Tunja, Colombia, 2 Universidad \\ Pedagógica y Tecnológica de Colombia, Facultad de Ciencias Básicas, Estudiante de Maestría en Ciencia \\ Biológicas. Tunja, Colombia., 3 Gobernación de Boyacá, S
}

*martinezd.camilo@gmail.com

\section{Abstract}

\section{Introducción:}

Sandfly are known for having vector species for the tropical disease known as leishmaniasis, endemic to West Boyacá; the municipality of Otanche displays one of the main focus for cutaneous leishmaniasis.

\section{OPEN ACCESS}

Citation: Martínez DC, Ávila $\mathrm{JL}$ and Molano F. Sandfly (Diptera: Psychodidae: Phlebotominae) present in an endemic area of cutaneous leishmaniasis in West Boyacá, Colombia. Colomb Med (Cali) 2019; 50(3): 192-200. http:// dx.org/1025100/cm.v50i3.3051

Received: 31 Mar 2017

Revised: 17 Sep 2017

Accepted:16 Dic 2018

\section{Keywords:}

Diptera, Psychodidae, Phlebotominae, Lutzomyia, Vector, Leishmania, Leishmaniasis cutánea, Colombia.

Palabras clave:

Diptera, Psychodidae, Phlebotominae, Lutzomyia, Vector, Leishmania, Leishmaniasis cutánea, Colombia.

Copyright: ( 2019. Universidad del Valle.

\section{Objetivo:}

To identify the species of sandfly present in an endemic area of cutaneous leishmaniasis in West Boyacá.

\section{Métodos:}

The search and collection of sandflies was carried out using CDC gravid traps, over a period of twelve hours (18:00- 06:00). Identification was carried out by revising the genitalia on both male and female samples under a microscope. The distribution took as reference households with a history of people infected with this disease, locating them intra, peri and extra domicile.

\section{Resultados:}

361 individuals were recollected (252 females and 109 male), belonging to 9 genres and 16 species. $60 \%$ of all recollected phlebotominae consists of Nyssomyia yuilli and Nyssomyia trapidoi. Other species recollected and relevant, due to vector precedent, are Lutzomyia hartmanni, Psychodopygus panamensis, Lutzomyia gomezi and Psychodopygus carrerai.

\section{Conclusión:}

It was established that, due to its abundance and vector precedent for the country and the area under study, Nyssomyia yuilli and Nyssomyia trapidoi constitute the species of phlebotominae which may be involved in the transmission of cutaneous Leishmaniasis in the region. 


\section{Conflicts of interest:}

There are no conflicts of interest on the part of the authors.

\section{Funding:}

This Project was framed on the focus study: Entomologic study for the Surveillance on Leishmaniasis

- Municipality of Otanche Centro Poblado Betania 2014. Department Health Secretary- Governorship of Boyacá (Estudio Entomológico para Vigilancia de Leishmaniasis - Municipio de Otanche Centro Poblado Betania, 2014. Secretaria Departamental de Salud-

Gobernación de Boyacá)

\section{Acknowledgments:}

Special thanks to the laboratory of the Health Secretary of Governorship of Boyacá, particularly, the entomology crew and the Vectortransmitted Diseases (ETV) crew, for their help with the logistics during the field trips and the laboratoryuse aspects. The technicians in the municipalities of Otanche and Pauna, for their in-field collaboration. The community of Vereda El Carmen, of the municipality of Otanche, for their kindness and willingness to authorize sampling in their households.

\section{Resumen}

\section{Introducción:}

Los flebótomos, son conocidos por tener especies vectoras de la enfermedad tropical Leishmaniasis, enfermedad que se presenta con carácter endémico en el occidente del departamento de Boyacá, donde el municipio de Otanche es uno de los principales focos de leishmaniasis cutánea.

\section{Objetivo:}

Identificar las especies de flebótomos presentes en una zona endémica de leishmaniasis cutánea en el occidente del Boyacá.

\section{Métodos:}

La búsqueda y recolección de los flebótomos se realizó con trampas CDC durante doce horas (18:00-06:00), tomando como referencia viviendas con antecedentes de personas que hubieran tenido la enfermedad, ubicándolas en el intra, peri y extradomicilio. La identificación se realizó por medio de revisión del órgano genital de machos y hembras al microscopio.

\section{Resultados:}

Se colectaron 361 individuos (252 hembras y 109 machos), pertenecientes a 9 géneros y 16 especies, de las cuales, el $60 \%$ de toda la flebótomofauna recolectada está representada por Nyssomyia yuilli y Nyssomyia trapidoi. Otras especies colectadas y con importancia por antecedentes vectoriales son Lutzomyia hartmanni, Psychodopygus panamensis, Lutzomyia gomezi y Psychodopygus carrerai.

\section{Conclusión:}

Se estableció, que por sus altas abundancias y por sus antecedentes vectoriales para el país y para la zona de estudio, Nyssomyia yuilli y Nyssomyia trapidoi, constituyen las especies de flebótomos que pueden estar implicadas en la transmisión de leishmaniasis cutánea en la zona de estudio

\section{Remark}

\section{1)Why was this study conducted?}

According to the epidemiologic precedent provided by the Public Health Surveillance System (SIVIGILA), there was a sporadic increase in the cases of cutaneous leishmaniasis in the municipality of Otanche between 2013 and 2014. The disease mainly affects people in the rural area, particularly in the settlements of El Carmen and Camilo. Due to this increase, it became necessary to carry out a study, in order to take preventive measures to stop propagation of this disease. An entomological study of the sandfly was necessary to determine possible vectors.

\section{2) What were the most relevant results of the study?}

An entomological study was undertaken in order to identify the species of sandfly and their relationships to households; this study abided by the regulations of the National Institute for Health and the Surveillance protocol on leishmaniasis (2014). 361 insects were recollected (252 females and 109 male), represented in 9 genres and 16 species. 32,8\% correspond to Nyssomyia yuilli, and 27,5\% to Nyssomyia trapidoi. Other species found include Lu. hartmanni, Ps. panamensis, Lu. gomezi and Ps. carrerai, all of them under 5\%.

\section{3) What do these results contribute?}

$\mathrm{N}$. yuilli may be involved in the cycle of domestic transmission in the area under study, whereas $\mathrm{N}$. trapidoi is suspected to be responsible for the cycle in the wild. Furthermore, the risk of transmission through a bite is uniform all across the village, due to the absence of meaningful differences in abundance and richness of the species of sandfly in the intra, peri and extra domicile areas. 


\section{Introduction}

Leishmaniasis constitutes an issue of public health, due to its morbidity, wide geographic distribution and complex transmission cycle, which includes different species of parasites, reservoirs and vectors ${ }^{1}$. On top of this, the transmission of this disease is increased by scarce and occasional studies which complete and update knowledge on the bionomics of transmitting or vector insects for the etiologic agent. This is relevant because changes in environmental variables, such as temperature, precipitation and gradual processes of sandfly settling can generate changes in the number of species, abundance, geographical distribution and behavior, thus making them the main risk factor for the transmission of this disease ${ }^{2-5}$.

Worldwide, over 12 million people are infected with cutaneous leishmaniasis, and 350 million are at risk of contagion ${ }^{6}$. In Latin America, Colombia appears as one of the endemic countries, under the category of HIGH RISK for contagion; one of the four countries with the highest number of reported cases, only topped by Brazil 7 . From year 2000, cutaneous leishmaniasis appears in West Boyacá as an epidemic 4, and, according to the Public Health Surveillance System of Boyacá (SIVIGILA), from 2011 there has been a sporadic increase in cases, especially in the municipality of Otanche, which led it to become one of the 25 municipalities with the highest rate of reported cases for cutaneous leishmaniasis nationwide in 2014, mostly affecting population in the rural area ${ }^{8}$.

Bearing this in mind, along with the fact that sandfly represents a risk to human population as vectors for Leshmania sp. (etiologic agent of leishmaniasis) ${ }^{5,9,10}$, and that the epidemiologic risk is determined by the existence and behavior of these insects ${ }^{2,3,5}$, this study aimed at identifying the species of sandfly present in an endemic area for cutaneous leishmaniasis in West Boyacá (Colombia).

\section{Materials and Methods}

\section{Area of study}

Due to the large number of positive cases of leishmaniasis reported between 2013 and 2014, (Public Health Surveillance System, department of Boyacá - SIVIGILA), sampling took place at "Vereda El Carmen", in the municipality of Otanche (average elevation 1,050 MASL and ecosystems proper to tropical humid forest) ${ }^{11,12}$.

\section{Sampling techniques}

The methodology for collection of adult sandfly samples followed the parameters proposed by the National Health Institute in its guideline: Protocol for Public Health Surveillance of leishmaniasis ${ }^{13}$.

During august, 2014, a total of 41 households were selected, whose inhabitants displayed active ulcers or scarring consistent with cutaneous leishmaniasis, showed evidence of recently having suffered the disease and/or inhabited the same household during the time of contagion. Three CDC traps were installed per night in each of the households: extra domicile (50 meters beyond the household), especially in forest areas; peri domicile (outside the household) in hen houses, barns or pigsties, and intra domicile (inside the household). The traps were left active for 12 hours straight, from 18:00 to 6:00 of the following day.

The material recollected in each of the traps was carefully separated, and the sandfly found were stored in $10 \mathrm{ml}$ vials, containing $70 \%$ alcohol for preservation and posterior identification in the entomology laboratory of the Health Secretary of Boyacá.

\section{Taxonomic identification of Sandfly}

Recollected individuals were cleared up by covering them with $10 \% \mathrm{KOH}$ (potassium hydroxide) and leaving it to act for 12 hours. After this time, $\mathrm{KOH}$ was removed and the material was washed using 70\% alcohol (for 60 minutes). Afterwards, the alcohol was removed, and the samples were poured into pods containing absolute phenol-alcohol (1:1) for 72 hours, in order to stop the process of transparentation, preserve the material and add contrast to the internal structures in order to facilitate identification ${ }^{14}$.

Once the entomologic material was cleared, the species were determined via the revision of the genitalia in both males and females along with the use of Young and Duncan ${ }^{15}$ and Galati ${ }^{16}$ 
taxonomic keys. Furthermore, each of the species was corroborated by the Quality Control program of the National Health Institute.

Permanent assembly was done in microscope slides with Canada balsam-phenol ${ }^{14}$ and later included in the Reference Collection of Phlebotominae of the Entomology Unit at the Public Health Departmental Laboratory of Boyacá.

\section{Data analysis}

Richness was determined based on the number of individuals of each species recollected and the relative abundance was the product of dividing the number of individuals recollected from each species into the total number of individuals captured ${ }^{17}$.

Deficit of coverage was calculated by subtracting the value for sample coverage from the unit (1). This analysis represents the probability that the next individual found belongs to a new, unregistered, species. Besides, 95\% confidence intervals were used for interpolation and extrapolation, using Bootstrap method ${ }^{18}$. All of the previous analyses were carried out using the iNEXT software, available online ${ }^{19}$.

Recollected individuals were counted for each sampled site: intra domicile, peri domicile and extra domicile, taking as a sampling unit each of the households selected, as this is the usual method for identifying anthropophilic species ${ }^{20,21}$. ANOVA analysis was carried out in order to determine whether there are meaningful differences between the number of species in each of the sites sampled and the relative abundance for each of these. All analyses were carried out using "Statistica" software $12{ }^{22}$.

\section{Ethical considerations}

This project was endorsed by the Departmental Health Secretary of Boyacá, as part of the entomological survey in a focus study for cutaneous leishmaniasis.

\section{Results}

361 sandflies were recollected (252 females and 109 males), belonging to 9 genres and 16 species. $32,8 \%$ and $27,5 \%$ correspond to Nyssomyia yuilli and Nyssomyia trapidoi respectively; followed, with a wide difference, by Trichopygomyia triramula, Psathyromyia barrettoi majuscula, Lutzomyia hartmanni, Lutzomyia sp. of pichinde, Evandromyia dubitans, Evandromyia walkeri, Evandromyia saulensis and Lutzomyia gomezi. The other 6 species were scarce, representing less than $1 \%$ of the total (Table 1 ).

Regarding sampling representativity, out of the 912 hours/CDC trap, distributed during 15 nights, the analysis of the rarefaction and extrapolation curve show that the number of species is expected to increase (Fig 1). However, by using the sample coverage analysis, the recollected species are estimated to represent $99 \%$ of those to be found, leaving a $1 \%$ possibility (coverage deficit) to find a new species as the sampling effort increases (Fig. 2).

It was determined that there is no significant difference among sandfly recollected on all three sampling sites, regarding richness (p: 0.949; p: >0.05) and abundance (p: 0.994; p: >0.05). (Fig. 3).

\section{Discussion}

The rarefaction and extrapolation curve describes an incomplete inventory of sandfly as the line shows an increase point ${ }^{18}$. Despite this, there is an approximation to the sandfly fauna present in the area of study, despite the lack of records. When contrasted with the species reported by Santamaría et $a l .{ }^{4}$, for West Boyacá, and which were not recollected for this study: Micropygomyia trinidadensis, Pintomyia ovallesi, Psathyromyia shannoni and Sciopemyia sordelli. Changes in the sandfly community, probably occurred over time, due to the changes in abiotic factors, such as relative humidity, temperature and precipitation. These factors directly influence the population dynamics of these insects ${ }^{23,24}$. Furthermore, the density of these vectors and the appearance or disappearance of new species can be related to climate factors and the behavior of human settlements, such as cultural and socio-economic activities, as well as transformation of habitats ${ }^{25-29}$. These activities are evident in the area in the changes caused on natural vegetal coverage for the farming of cacao and coffee, wood extraction and construction of houses ${ }^{11,12}$. 
Table 1. Relative Richness and abundance of Sandfly recollected at “Vereda El Carmen”, Municipality of Otanche (Boyacá - Colombia)

\begin{tabular}{llrrrr}
\hline Genre & \multicolumn{1}{c}{ Species } & \multicolumn{1}{c}{ Total } & \multicolumn{1}{c}{ Abundancia relativa } \\
\hline Nyssomyia & yuilli & 83 & 35 & 118 & 0.327 \\
Nyssomyia & trapidoi & 78 & 21 & 99 & 0.274 \\
Trichopygomyia & triramula & 22 & 26 & 48 & 0.133 \\
Psathyromyia & barrettoi & 12 & 10 & 72 & 0.061 \\
Lutzomyia & hartmanni & 8 & 7 & 15 & 0.042 \\
Lutzomyia & sp. de pichinde & 9 & 4 & 13 & 0.036 \\
Evandromyia & dubitans & 13 & 0 & 12 & 0.036 \\
Evandromyia & walkeri & 9 & 3 & 7 & 0.033 \\
Evandromyia & saulensis & 7 & 0 & 5 & 0.019 \\
Lutzomyia & gomezi & 5 & 0 & 2 & 0.014 \\
Pressatia & camposi & 2 & 0 & 2 & 0.006 \\
Psychodopygus & panamensis & 2 & 0 & 2 & 0.006 \\
Psychodopygus & carrerai & 0 & 2 & 1 & 0.006 \\
Pintomyia & serrana & 1 & 0 & 1 & 0.003 \\
Lutzomyia & strictivila & 1 & 0 & 1 & 0.003 \\
Brumptomyia & leopoldi & & 109 & 361 & 0.003 \\
Total & & 252 & & &
\end{tabular}

Species relevant for their vector and abundance background are N. yuilli and N. trapidoi ${ }^{30}$, since they represent $60 \%$ of all sandfly fauna recollected. Other species with a vector background are Lu. hartmanni, Ps. panamensis, Lu. gomezi and Ps. carrerai ${ }^{4,26-28,30-33}$, although their abundance rate is under $5 \%$.

$\mathrm{N}$. yuilli was more abundant in intra and peri domicile, which suggests an adaptation to the environments modified by human colonization ${ }^{4}$. It has also been found naturally infected by unidentified flagellates in Brazil and in the municipality of Leticia (Colombia) ${ }^{9,31,32}$. For the case of Colombia, Ferro and Morales ${ }^{34}$, found species with unidentified flagellates. Santamaria et al. ${ }^{4}$ presented the first positive vector incrimination report for N. yuilli, as a vector for Le. Panamensis; reporting naturally infected females in the municipalities of Otanche and Pauna, in West Boyacá, at the foothills of the Magdalena Medio Valley.

N. trapidoi has been identified as a vector for Le. panamensis in Ecuador ${ }^{35,36}$, and in Panama ${ }^{37}$. For the Colombian case, this species is considered a primary vector in different sites, reported in 12 out of the 32 departments. In Nariño, Tolima, Antioquia and Santander, it is known as a vector for Le. panamensis ${ }^{30,32,33,38-40}$; natural infection by parasites of Leishmania braziliensis complex 39 was also reported in Santander ${ }^{39}$. In the municipalities of Otanche and Pauna (Boyacá), females of N. trapidoi have been found displaying flagellate forms of Leishmania sp. But it has not been possible to establish a confirmation for the species ${ }^{4,41}$. Because of its background as vector and greater extra domicile abundance, as well as forest habitat, this species is suspected to be involved in the wild cycle for transmission of cutaneous leishmaniasis in the area under study.

Ty. triramula, the species displaying the third place in abundance, does not have differentiated anthropophilic characteristics, nor reported medical relevance; the high number of individuals preferring peri domicile locations recollected during the study may be due for positive phototropism ${ }^{42,43}$. Another species with a vector background is Lu. hartmanni, which has been

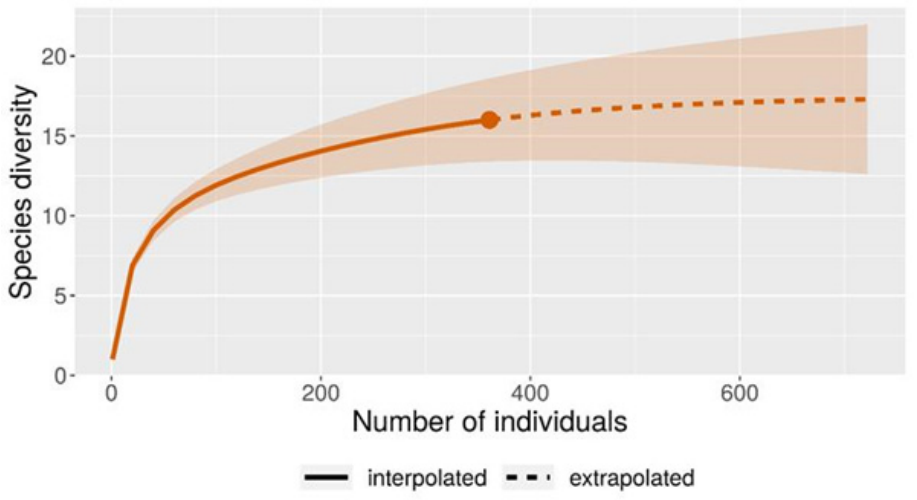

Figure 1. Rarefaction and extrapolation curve, based on the size of the sample (solid line) and extrapolation (broken line) for the species of sandfly recollected at Vereda El Carmen, Municipality of Otanche (Boyacá- Colombia).



Figure 2. Sample coverage curve, based on rarefaction (solid line) and extrapolation (broken line) for species of sandfly recollected at "Vereda El Carmen", municipality of Otanche (Boyacá - Colombia) 


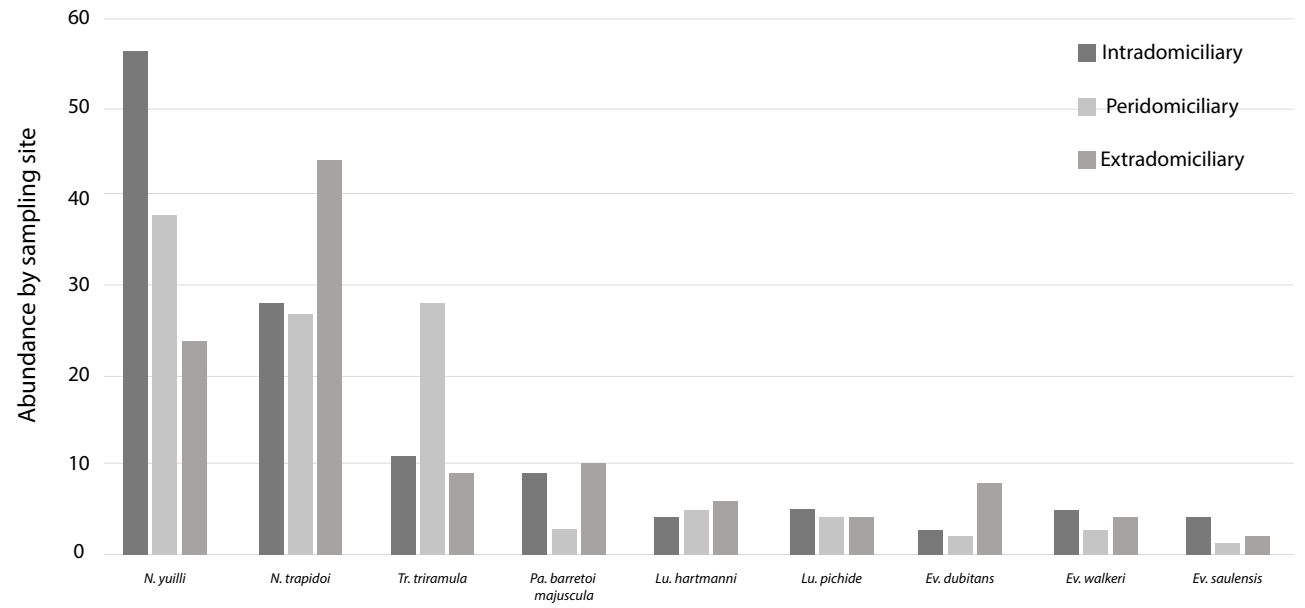

Figure 3. Abundance of species of sandfly present per sampling site: intra domicile, peri domicile and extra domicile.

determined to be a vector of Le. (Viannia) colombiensis, a parasite known as an etiologic agent of cutaneous leishmaniasis in Costa Rica, Panama, Peru, Colombia and Ecuador ${ }^{15,44-46}$. For the latter, Lu. Hartmanni has also been found to be infected with Le. (Viannia) equatorensis ${ }^{36,47,48}$. The other species of sandfly reported in this study have no proven relevance in the epidemiologic cycle of leishmaniasis, other than a taxonomic interest.

Since there are no meaningful differences among any of the sampling sites (intra, peri and extra domicile) regarding abundance and number of species of sandfly found, this is evidence that the closeness of households to the forest line fosters a situation where people are highly likely to come into contact with the vectors, and therefore, risking contagion of cutaneous leishmaniasis ${ }^{49}$. Furthermore, there can be an increase in new cases, due to the entrance of people into the natural habitat of these insects, evident in sociocultural activities such as plant extraction, agriculture, wood chopping, or simply by living nearby the forest area ${ }^{50-51}$. Even people who do not have activities in or nearby the forest, such as the infants or the elderly, may be infected or at risk of becoming sick ${ }^{52}$.

Finally, based on the data acquired in this study, it can be established that, due to its high abundance and vector background for the country and the area under study, N. yuilli and N. trapidoi constitute the vector species suspected to transmit cutaneous leishmaniasis in the area under study. The first one is likely to be involved in the domestic transmission cycle, and the second one in the wild transmission cycle. Likewise, the risk of acquiring the disease by sandfly bite is the same in any part of the settlement: inside the households, around the households and in the forest.

In order to better understand the epidemiology of the disease in the area, and suggest effective prevention and control programs, it is necessary to carry out more detailed studies on the ecology of the population of sandfly, such as feeding preferences, biting and rest behavior; and also studies in different times of the year, with longer sampling time, but above all, performing natural infection analysis in order to accurately pinpoint a species with the potential to be vector of cutaneous leishmaniasis and consequently identifying the species of the parasite responsible for the disease.

\section{References}

1. Pan America Health Organization. Leishmaniasis: Epidemiological Report of the Americas. Report Leishmaniases $N^{\circ}$ 1; 2013 Available from: http://www.paho.org/hq/index.php?option=com docman\&task=doc_view\&gid=21608\&ltemid=. Accessed 2018 December 7.PAHO . Leishmaniasis: Epidemiological Report of the Americas. 2013. [2018 December 7]. Available from: http://www.paho.org/hq/ index.php?option=com_docman\&task=doc_view\&gid=21608\&ltemid= [Google Scholar]

2. Travi B, Montoya J, Gallego J, Jaramillo C, Llano R, Vélez ID. Bionomics of Lutzomyia evansi (Diptera: Psychodidae) vector of visceral leishmaniasis in northern Colombia. J Med Entomol. 1996;33:278-85. DOI: 10.1093/jmedent/33.3.278 
3. Davies CR, Reithinger R, Campbell-Lendrum D, Feliciangeli D, Borges R, Rodriguez N. The epidemiology and control of leishmaniasis in Andean countries. Cad Saúde Pública. 2000;16(4):925-50. DOI: $10.1590 / \mathrm{s} 0102-311 \times 2000000400013$

4. Santamaría E, Ponce N, Zipa Y, Ferro C. Presencia en el peridomicilio de vectores infectados con Leishmania (Viannia) panamensis en dos focos endémicos en el occidente de Boyacá, piedemonte del calle del Magdalena Medio. Biomédica. 2006;26(Supl 1):82-94. DOI: 10.7705/biomedica.v26i1.1503

5. Molina JA, Ortiz MI, Guhl F. Seasonality of Lutzomyia fairtigi (Diptera: Psychodidae: Phlebotominae), a species endemic to Eastern Colombia. Mem Inst Oswaldo Cruz. 2008;103(5):477-782. DOI: 10.1590/ S0074-02762008000500012

6. WHO. Leishmaniasis: Epidemiological situation; 2018. Available from: https://www.who.int/leishmaniasis/ burden/en/. Accessed 2018 October 15

7. OPS; OMS. Leishmaniasis. Informe Epidemiológico de las Américas. Informe de Leishmaniasis № 6; 2018. Available from: http://iris.paho.org/xmlui/bitstream/handle/123456789/34858/LeishReport6_spa. pdf?sequence=5\&isAllowed=y. Accessed 2018 November 15.

8. Instituto Nacional de Salud. Boletín Epidemiológico Semanal: Semana Epidemiológica Número 10 de 2014. Available from: http://www.ins.gov.co/boletin-epidemiologico/Boletn\%20Epidemiolgico/2014\%20 Boletin\%20epidemiologico\%20semana\%2010.pdf. Accessed 2017 January 17.

9. Lainson RR, Shaw JJ. Infective stages of Leishmania in the sandfly vector and some observations on the mechanism of transmission. Mem Inst Oswaldo Cruz. 1987;82:421-41. DOI: 10.1590/s007402761987000300015

10. Sharma U, Singh S. Insect vectors of Leishmania: distribution, physiology and their control. J Vector Borne Dis. 2008;45(4):255-72. DOI: 10.1201/9781420088489.ch8S

11. Gobernación de Boyacá. Esquema de Ordenamiento Territorial Otanche-Boyacá 2001. Otanche: Gobernación de Boyacá; 2006. 62 p.

12. Guerrero Vásquez W. Plan Municipal de Desarrollo 2012-2015 “Otanche Vamos Pa'lante”. Otanche: Consejo Municipal de Otanche; 2012. 223 p.

13. Instituto Nacional de Salud. Guía: Protocolo para la Vigilancia en Salud Pública de Leishmaniasis; 2006. Available from: http://www.ins.gov.co/temas-de-interes/Leishmaniasis\%20viceral/01\%20protocolo\%20 Leishmaniasis.pdf. Accessed 2016 July 27.

14. Fuenzalida D. Técnica de clarificación y montaje para determinación de flebótomos. en: actas segunda reunión Red de Investigación de las Leishmaniasis en Argentina. Puerto Iguazú: Instituto Nacional de Medicina Tropical (INMeT); 2011:p. 34-37.

15. Young DG, Duncan MA. Guide to the identification and geographic distribution of Lutzomyia sand flies in Mexico the West Indies, Central and South America (Diptera: Psychodidae). Gainesville: Memories of the American Entomological Institute; 1994.

16. Galati EAB. Phlebotominae (Diptera, Psychodidae): Classificacao, Morfologia, Terminologia e Identificacao de Adultos. Sao Paulo: Departamento de Epidemiologia. Faculdade de Saúde Pública. Universidade de Sao Paulo; 2013.

17. Magurran A. Measuring biological diversity. Australia: Blackwell Science Ltd; 2004.

18. Chao A, Jost L. Coverage-based rarefaction and extrapolation: standardizing samples by completeness rather than size. Ecology. 2012; 93(12):2533-2547. doi: 10.1890/11-1952.1

19. iNEXT (iNterpolation and EXTrapolation) Online. Sample Completeness Curve; 2016. Available from: https://chao.shinyapps.io/iNEXTOnline/. Accessed 2019 June 4.i

20. Ogusuku E, Paz L, Monje J, Perez JE, Nieto E, Guerra H. El hombre como fuente de sangre para Lutzomyia spp. (Dipetra: Psychodidae) andinos. Nota científica. Rev Peruana Entomol. 1999; 34(1): 56.

21. Organización Mundial de la Salud. Control de las leishmaniasis. Ginebra: OMS Serie de Informes Técnicos 949; 2010.

22. Statsoft. Statistica (data analysis software system and computer program manual). Versión 12. StatSoft Inc. Tulsa, Ok, USA. 2014.

23. Bejarano EE, Sierra D, Vélez ID. Novedades en la distribución geográfica del grupo verrucarum 
(Diptera: Psychodidae) en Colombia. Biomédica. 2003;23:341-50. DOI: 10.7705/biomedica.v23i3.1228

24. Vergara D, Carrillo LM, Vélez ID, Bejarano EE. Primer informe de Lutzomyia yuilli Young \& Porter, 1972 y Lutzomyia triramula (Fairchild \& Hertig 1952) (Diptera: Psychodidae) en el departamento de Caldas, Colombia. Biota Neotropica. 2008;8(1):251-53. DOI: 10.1590/S1676-06032008000300022.

25. Perruolo GJ. Ecología de los flebótomos (Diptera, Psychodidae) y su influencia sobre la leishmaniasis tegumentaria en zonas endémicas del estado Táchira, Venezuela. Kasmera. 1984;12(1-4):74-95.

26. Alexander JB, Agudelo LA, Navarro F, Ruiz F, Molina J, Aguilera G, et al. Phlebotomine sandflies and leishmaniasis risks in Colombian coffee plantations under two systems of cultivation. Med Vet Entomol. 2001;15(4):364-73. DOI: 10.1046/j.0269-283x.2001.00322.x

27. Azevedo AC, Souza NA, Meneses CR, Costa WA, Costa SM, Lima JB, Rangel EF. Ecology of sand flies (Diptera: Psychodidae: Phlebotominae) in the north of the state of Mato Grosso, Brazil. Mem Inst Oswaldo Cruz. 2002;97(4):459-64. DOI: 10.1590/s0074-02762002000400002

28. Barata RA, França da Silva JC, Mayrink W, Costa da Silva J, Prata A, Lorosa ES, et al. Aspectos da ecologia e do comportamento de flebotomíneos em área endêmica de leishmaniose visceral, Minas Gerais. Rev Soc Bras Med Trop. 2005; 38(5): 421-25. DOI: 10.1590/S0037-86822005000500012

29. Contreras G. Lutzomyia spp. (Diptera: Psychodidae) en zonas cafeteras de la región andina colombiana: taxonomía e importancia médica. Medellín: Universidad Nacional de Colombia, Facultad de Ciencias; 2013.

30. Travi BL, Montoya J, Solarte Y, Lozano L, Jaramillo C. Leishmaniasis in Colombia. I. Studies on the phlebotomine fauna associated with endemic foci in the Pacific Coast region. Am J Trop Med Hyg. 1988; 39(3): 261-266.

31. Arias JR, Miles MA, Naiff RD, Povoa MM, de Freitas RA, Biancardi CB, et al. Flagellate infections of Brazilian sand flies (Diptera: Psychodidae): isolation in vitro and biochemical identification of Endotrypanum and Leishmania. Am J Trop Med Hyg. 1985;34(6):1098-1108. DOI: 10.4269/ajtmh.1985.34.1098

32. Vélez ID, Ospina S, Henao G, Lepape P, Correa M, Wolff M, et al. Epidemiología de la leishmaniasis en San Roque, Antioquia. Boletín Epidemiológico de Antioquia. 1987; 12: 354-59.

33. Young DG, Morales A, Kreutzer RD, Alexander JB, Corredor A, Tesh RB. Isolation of Leishmania braziliensis (Kinetoplastida: Trypanosomatidae) from cryopreserved Colombian sand flies (Diptera: Psychodidae). J Med Entomol. 1987; 24: 587-89. DOI: 10.1093/jmedent/24.5.587

34. Ferro C, Morales A. Flebótomos de Colombia: estudios realizados por el Laboratorio de Entomología 1966-1997. En: Toro G, Hernández CA, Raad J (eds). Instituto Nacional de Salud 1917-1997: una historia, un compromiso. Santa Fé de Bogotá: Instituto Nacional de Salud; 1998. p. 219-33.

35. Hashiguchi Y, Gomez EA, De Coronel VV, Mimori T, Kawabata M. Biting activity of two antropophilic species of sandflies, Lutzomyia, in an endemic area of leishmaniasis in Ecuador. Ann Trop Med Parasitol. 1985; 79: 533-38. DOI: 10.1080/00034983.1985.11811959

36. Le Ponti F, Leon R, Guerrini F, Gantier JC, Mouchet J, Echeverria R, et al. Leishmaniasis in Ecuador. 3. Lutzomyia trapidoi, vector of Leishmania panamensis. Ann Soc Belg Med Trop. 1994;74(1):23-28.

37. Christensen HA, Fairchild GB, Herre A, Johnson CM, Young DG, De Vasquez AM. The Ecology of cutaneous leishmaniasis in the Republic of Panama. J Med Entomol. 1983;20:463-84. DOI: 10.1093/ jmedent/20.5.463

38. Morales A, Corredor A, Cáceres E, Ibagos AL, Rodríguez Cl. Aislamiento de tres cepas de Leishmania a partir de Lutzomyia trapidoi en Colombia. Biomédica. 1981;4:37-41. DOI: 10.7705/biomedica.v1i4.1802

39. Loyola EG, Álzate A, Sánchez A, González A. Epidemiology of a natural focus of Leishmania braziliensis in the Pacific lowlands of Colombia. III Natural infections in wilds mammals. Trans Roy Soc Trop Med Hyg. 1988; 82(3): 406-07. DOI: 10.1016/0035-9203(88)90136-8

40. Duque P, Vélez ID, Morales M, Sierra D. Sand flies fauna involved in the transmission of cutaneous leishmaniasis in Afro-Colombian and American communities of Chocó, Pacific coast of Colombia. Neotrop Entomol. 2004;33(2):255-64. DOI: 10.1590/S1519-566X2004000200018

41. Molina JA. Determinación de la fauna flebotominea en el noroccidente de Boyacá. Implicación de Lutzomyia trapidoi como especie vectora en el foco de leishmaniasis de la Zambera. Bogotá: Universidad de los Andes; 1995.

42. Chaniotis BN, Correa MA. Comparative flying and biting of Panamian phlebotomine sand flies in mature forest and adjacent open space. J Med Entomol. 1974;11:115-16. DOI: 10.1093/jmedent/11.1.115 
43. Rutledge LC, Ellenwood DA, Johnston L. An analysis of sandfly light trap collection in the Panama Canal Zone (Diptera: Psychodidae). J Med Entomol. 1975;12(2):179-83. DOI: 10.1093/jmedent/12.2.179

44. Kreutzer RD, Corredor A, Grimaldi G. Jr, Grogl M, Rowton ED, Young DG, et al. Characterization of Leishmania colombiensis sp. $\mathrm{n}$ (Kinetoplastida: Trypanosomatidae), a new parasite infecting humans, animals, and phlebotomine sand flies in Colombia and Panama. Am J Trop Med Hyg. 1991;44(6):662-75. DOI: 10.4269/ajtmh.1991.44.662

45. Agudelo L, Uribe J, Sierra D, Ruiz F, Vélez D. Presence of America cutaneos Leishmaniasis vectors surrounding the city of Medellin, Colombia. Mem Inst Oswaldo Cruz. 2002;95:641-42. DOI: 10.1590/S007402762002000500008

46. Pérez A, Bejarano E. tRNASer (UCN) Mitocondrial de Lutzomyia hartmanni predicción de la estructura secundaria del tRNASer (UCN) mitocondrial del flebotomíneo Lutzomyia hartmanni (Díptera: Psychodidae). Acta Biolo Colomb. 2011;16:87-94. DOI: 10.15446/abc

47. Corredor A, Kreutzer RD, Tesh RB , Boshell J, Palau MT, Caceres E, et al. Distribution and etiology of leishmaniasis in Colombia. Am J Trop Med Hyg. 1990;34:440-46. DOI: 10.4269/ajtmh.1990.42.206

48. Masato F, Motonari S, Yoko A, Tatsuyuki M, Gomez E, Hashiguchi Y. Natural infection of Lutzomyia hartmanni with Leishmania (Viannia) equatorensis in Ecuador. Parasitol Int. 1998;47: 21-26. DOI: 10.1016/ S1383-5769(98)00009-9

49. Andrade SL. Leishmaniose tegumentar americana em área de ocupação recente na periferia da Cidade de Manaus, Estado do Amazonas, Brasil. Rio de Janeiro: Departamento de Medicina Tropical, Instituto Oswaldo Cruz; 1997.

50. Talhari S, Arias JR, Cunha MGS, Naiff RD, Naiff MF, Alves De Freita R, et al. Leishmaniose no Estado do Amazonas - aspectos epidemiológicos clínicos e terapêuticos. An Bras Dermatol. 1988;63:433-38.

51. Guerra JAO, Barros MLB, Guerra MVF, Talhari S, Paes MG. Leishmaniose tegumentar no Município de Manaus - aspectos epidemiológicos. Rev Soc Bras Med Trop. 1998;31:172. DOI: 10.1590/S0102311X2007000900029

52. Oliveira JA, Santana JA, Aguiar LI, Vale MG, Gomez M. Epidemiologia da leishmaniose tegumentar na comunidade Sao Joao, Manaus, Amazonas, Brasil. Cad Saúde Pública. 2006;22(11):2319-27. DOI: 10.1590/S0102-311X2006001100006 